\title{
La Question du sens au Moyen Âge. Hommage au professeur Armand Strubel
}

\section{Maria Colombo Timelli}

\section{(2) OpenEdition}

1 Journals

\section{Édition électronique}

URL : https://journals.openedition.org/studifrancesi/20651

DOI : 10.4000/studifrancesi.20651

ISSN : 2427-5856

Éditeur

Rosenberg \& Sellier

\section{Édition imprimée}

Date de publication : 1 décembre 2019

Pagination : $543-544$

ISSN : 0039-2944

\section{Référence électronique}

Maria Colombo Timelli, «La Question du sens au Moyen Âge. Hommage au professeur Armand Strubel », Studi Francesi [En ligne], 189 (LXIII | III) | 2019, mis en ligne le 01 mars 2020, consulté le 12 novembre 2021. URL : http://journals.openedition.org/studifrancesi/20651 ; DOI : https://doi.org/10.4000/ studifrancesi.20651

Ce document a été généré automatiquement le 12 novembre 2021.

\section{(c) 9 (i) $\Theta$}

Studi Francesi è distribuita con Licenza Creative Commons Attribuzione - Non commerciale - Non opere derivate 4.0 Internazionale. 


\title{
La Question du sens au Moyen Âge. Hommage au professeur Armand Strubel
}

\author{
Maria Colombo Timelli
}

\section{RÉFÉRENCE}

La Question du sens au Moyen Âge. Hommage au professeur Armand Strubel, Paris, Champion, 2017, $773 \mathrm{pp}$.

1 Ce gros recueil d'articles se propose de rendre hommage à un des plus grands spécialistes du Moyen Âge français, en reprenant, dans les quatre parties qui le composent, les sujets qu'il a le plus fréquentés et innovés, que ce soit par des éditions critiques ou des réflexions théoriques. $\mathrm{Vu}$ la richesse du volume, nous ne pourrons qu'évoquer sommairement les sujets de chaque article (les contributions centrées sur le $\mathrm{XV}^{\mathrm{e}}$ siècle ont été signalées dans SF188, p. 335).

Première partie: La Rose, Renart et le Graal... et leurs suites

3 Pierre-Yves Badel revient sur les descriptions de la rose dans la section de Guillaume de Lorris pour en souligner deux particularités: fleur sans épines, elle est d'abord parfum, et ce jusqu'au moment du baiser par l'Amant (pp. 39-53). Jacqueline Cerquiglini-Toulet s'interroge sur les signes du succès du Roman de la Rose (manuscrits anciens, traductions modernes) et sur les raisons qui l'ont déterminé, au premier chef sa richesse et les multiples lectures qu'il autorise (pp. 55-64). Selon Joëlle Ducos et Jean-René Valette la dualité du Roman de la Rose est confirmée par la distribution du mot semblance, récurrent dans la partie de Guillaume de Lorris, absent dans celle de Jean de Meun: ceci reflète deux doctrines différentes de l'image, l'une centrée sur l'idéologie courtoise, l'autre ouverte sur le monde (pp.65-82). Valérie Fasseur commente la dispute qui prend place au début de la section de Jean de Meun, l'Amant accusant Raison de n'avoir pas voilé le mot couilles, dans le cadre complexe de l'allégorie médiévale (pp. 83-100). 
Christine Ferlampin-Acher vérifie l'influence du Roman de la Rose sur Guillaume de Palerne (ca 1280) et sur Artus de Bretagne (fin XIII - début XIV siècle): dans le premier, le symbolisme animal prévaut sur l'imaginaire floral, alors que le second corrige le symbolisme floral en le mettant à distance (pp. 101-116). Frank Lestringant analyse le portrait de Jean de Meun dans les Hommes illustres d'André Thevet (1583): inspiré en grande partie à Claude Fauchet, ce chapitre recommande la lecture du Roman de la Rose sans pour autant donner aucune information sur son contenu (pp. 137-150). L'analyse de trois passages du Roman de Renart (Moniage, Confession, Création) permet à Roger Bellon d'exclure toute interprétation allégorique du texte: on n'y trouve de fait que des contes à rire reposant sur la parodie et jouant sur les ressources de l'anticléricalisme et de l'antiféminisme (pp. 167-190). Jean-Marie Fritz enquête sur le rapport exceptionnel qui relie Renart à la voix et au silence: le goupil glapit certes, mais surtout il maitrise la parole et la voix, voire le silence; capable de se taire et d'écouter, ce héros exceptionnel sait également réfléchir (pp.191-205). Bernard Ribémont relève les remarques sur la justice et les hommes de loi dans Fauvel; bien que discrètes, celles-ci soulignent surtout la nécessité, pour le bon fonctionnement du royaume, d'une justice humaine proche de la justice de Dieu (pp. 207-214). L'interprétation de toute œuvre médiévale est, aux yeux de Patrick Moran, essentielle et multiple: les grands cycles, le Cycle Vulgate en particulier, imposent à l'herméneute moderne de prendre en compte à la fois le sens de chaque œuvre et celui de l'ensemble (pp. 215-226).

Deuxième partie: Allégorie et analogie: les techniques du sens

Françoise Laurent souligne l'originalité de la Vie de saint Thomas Becket de Guernes de Pont-Sainte-Maxence: œuvre hagiographique, elle trouve son sens dans une lecture typologique qui encadre les événements historiques dans une dimension universelle et eschatologique (pp. 293-309). Figure majeure dans l'historiographie troyenne, Fortune est au centre du questionnement sur le destin des civilisations: Catherine CroizyNaquet montre comment l'Historia Destructionis Troiae de Guido delle Colonne et son premier traducteur en prose française dissocient Fortune de la Providence divine (pp. 311-326). La branche VI du Roman de Renart, "Les Vêpres de Tibert", est la seule à se désigner comme une "fable": à partir de ce constat, Francis Gingras relève néanmoins que ce récit met à distance la fable ésopique et sa moralité (pp.327-346). C'est la "pensée symbolique" en tant que composante du récit qui constitue, selon Jean-Jacques Vincensini, la clé de lecture la plus efficace pour aborder un roman aussi "réaliste" que L'Escoufle de Jean Renart (pp. 347-362).

Troisième partie: Les méandres du sens

7 La Genèse elle-même a fait l'objet de quelques réécritures médiévales: Marie-Pascale Halary s'interroge sur le sens à attribuer aux deux bestournements du récit centré sur Adam et Ève dans quelques manuscrits du Roman de Renart et dans le fabliau $\mathrm{Du}$ con qui fu fait a la besche (pp.447-458). La locution estrillier Fauvel a connu de nombreuses variantes ainsi que des représentations iconographiques variées: Sylvie Lefèvre en trace le parcours à partir du Roman de Fauvel jusqu'au Quart Livre de Rabelais (pp. 459-476). L'auteur de l'Ovide moralisé ne se limite pas à traduire les Métamorphoses en français: comme le montre Marilène Possamaï, il réalise une véritable somme en exploitant tout le matériau mythographique dont il dispose afin de fournir un commentaire exhaustif des quinze livres ovidiens (pp.477-494). Les deux songes nocturnes qui annoncent au Viking Rollon sa destinée se retrouvent dans trois chroniques des $\mathrm{XI}^{\mathrm{e}}$ et $\mathrm{XII}^{\mathrm{e}}$ siècles: le De moribus et actis primorum Normanniae Ducum, le 
Roman de Rou de Wace et la Chronique des ducs de Normandie de Benoît de Sainte-Maure; Laurence Mathey-Maille montre comment la lettre et le sens de la vision s'y juxtaposent en révélant en même temps une vision de l'histoire providentialiste - chez les deux premiers auteurs - ou pragmatique, chez Benoît (pp. 495-506). Roman épique franco-italien, Aquilon de Bavière se prête à une double lecture: comme le montre JeanClaude Vallecalle, Raffaele da Verona réécrit la geste rolandienne en la reliant à la complexité du devenir historique (pp. 507-517). Jean Maurice analyse la tradition des Bestiaires en se penchant en particulier sur les gloses: leur évolution n'est pas étrangère à la disparition du genre même à la fin du XIII ${ }^{\mathrm{e}}$ siècle (pp. 519-534). Adaptation du Roman de la Rose, le Chemin de Povreté et de Richesse de Jacques Bruyant (1342) reprend la métaphore du chemin de Richesse de Jean de Meun; selon Élisabeth Pinto-Mathieu, ce n'est pas d'une apologie du travail qu'il s'agit, mais bien d'une équivoque sur le sexe, dans la veine du comique médiéval, misogyne et anti-matrimonial (pp.535-556). Philippe Haugeard se propose d'analyser la logique qui préside à l'usage de la richesse de la part des deux couples que forment Girart et Berthe, Charles et Elissent dans Gérard de Roussillon, usage qui, grâce aux deux personnages féminins, en vient à déterminer le dénouement du récit (pp. 591-604). Réfutant quelques lectures traditionnelles du Jeu de Robin et Marion, Jean-Pierre Bordier y voit une pièce sur le mariage: action, poésie, chant et danse s'y accordent dans une célébration qui ne nie pas les dangers qui guettent cette institution. Le Jeu pourrait même avoir été composé "pour célébrer un mariage et faire danser les invités» (pp.625-644, citation p.643). Dominique Boutet examine le fonctionnement de la parodie dans Audigier, dont le rapport avec la chanson de geste d'une part, avec les fabliaux de l'autre, demeure problématique: à ses yeux, ce poème recherche une intergénéricité qui aurait pour but le «seul plaisir du jeu, d'une subversion gratuite dépourvue de sens» (pp. 645-661, citation p. 661). Claudio Galderisi examine le traitement des laboratores en tant que "matière littéraire": leur présence dans certains récits médiévaux incarnerait un écart esthétique et une altérité littéraire par rapport aux genres fondés sur les deux autres ordres, bellatores et oratores (pp. 663-674).

Quatrième partie: Questions de mots

Un mot figure au centre de la contribution de Claude Thomasset, feindre et dérivés, dont on peut regretter, sinon la disparition, l'appauvrissement sémantique dans l'évolution de l'ancien français à la langue contemporaine (pp.695-701). C'est enfin la locution figée le faire qu'Olivier Soutet se propose de définir sur la base de la théorie psychomécanique du langage, en la distinguant des emplois de faire absolu et de faire + SN (pp. 739-753).

Outre l'Index des noms et des œuvres (pp.757-768), toujours précieux dans ce genre d'ouvrages, on signalera l'intérêt de la biographie d'Armand Strubel, offerte en début de volume, pp. 25-36. 